Article

\title{
Understanding the Implementation Challenges of Urban Resilience Policies: Investigating the Influence of Urban Geological Risk in Thessaloniki, Greece
}

\author{
Vangelis Pitidis $1, *\left(\mathbb{D}\right.$, Deodato Tapete ${ }^{2,3} \mathbb{D}$, Jon Coaffee ${ }^{1,4}$, Leon Kapetas ${ }^{5}$ and \\ João Porto de Albuquerque 1,6 (D) \\ 1 Warwick Institute for the Science of Cities, University of Warwick, Coventry CV4 7AL, UK; \\ J.Coaffee@warwick.ac.uk (J.C.); J.Porto@warwick.ac.uk (J.P.d.A.) \\ 2 Italian Space Agency (ASI), 00133 Rome, Italy; deodato.tapete@asi.it \\ 3 Formerly at British Geological Survey (BGS), Keyworth, Nottingham NG12 5GG, UK \\ 4 Department of Politics and International Studies, University of Warwick, Coventry CV4 7AL, UK \\ 5 Department of Engineering, University of Cambridge, Cambridge CB2 1PZ, UK; 1k411@cam.ac.uk \\ 6 Centre for Interdisciplinary Methodologies, University of Warwick, Coventry CV4 7AL, UK \\ * Correspondence: V.Pitidis@warwick.ac.uk; Tel.: +44-(0)-754-804-8879
}

Received: 16 July 2018; Accepted: 1 October 2018; Published: 7 October 2018

\begin{abstract}
Urban Resilience has recently emerged as a systematic approach to urban sustainability. The malleable definition of resilience has rendered its operationalisation an intriguing task for contemporary cities trying to address their organisational problems and confront uncertainty in a holistic manner. In this article we investigate the implementation challenges emerging for Resilient Strategies by the inattention paid to urban geological risk. We conceptualise urban geological risk as the combination of urban geohazards, geological vulnerability and exposure of the built environment and focus on the case study of Thessaloniki, Greece, a city that joined the 100 Resilient Cities initiative in 2014 and published its "Resilience Strategy 2030" (RS) in 2017. After a review of the RS, historical records of natural hazard events and with evidence gathered through interviews with city officials, we emphasize on earthquakes and surface flooding as the most relevant geohazards for Thessaloniki to tackle in its journey towards urban resilience. First, we examine geological vulnerability to earthquakes in conjunction with exposure of the built environment, as an outcome of ageing building stock, high building densities and the urban configuration, in Acheiropoietos neighbourhood, within the historic centre of the city. Then, we explore geological risk to surface flooding in Perea, in Thermaikos Municipality, with a particular focus on flash floods, by demonstrating how limited consideration of local geomorphology as well as semi-regulated urban expansion and its limited connection with emergency planning increase exposure of the built environment to surface flooding. Finally, we come up with the major implementation challenges Thessaloniki's RS faces with regard to urban geohazards.
\end{abstract}

Keywords: geohazards; urban resilience; implementation; 100 Resilient Cities; Thessaloniki

\section{Introduction}

Protection of urban environments against uncertainty has always been a stimulating task for local authorities around the world. As landscapes worldwide are becoming more urbanized, the complexity and sensitivity of cities are exponentially increasing [1]. Thus, the need for a new direction in strategic planning and design in order to deal with this new urban reality is apparent today. Urban resilience is a debated concept, which emerged as an answer to this problem after various permutations and amalgamations of previously applied concepts in various scientific disciplines [2,3], evangelising 
a secure pathway to sustainability through multidisciplinary, holistic management of urban anomalies. However, the malleability of the term, in conjunction with the variety of disciplinary fields in which it is being applied, has generated confusion and policy implementation gaps [4].

The challenge of incorporating geological risk due to urban geohazards into strategic urban policies is a vivid example of this confusion. On the one hand, many important global urban development institutions, such as the UNISDR, are acknowledging the fundamental connection between hazards and resilience, framing their definition of the term as 'the ability of a system, community or society exposed to hazards to resist, absorb, accommodate, adapt to, transform and recover from the effects of a hazard in a timely and efficient manner, including through the preservation and restoration of its essential basic structures and functions through risk management' [5].

On the other hand, other institutions have adopted a softer approach, reflecting the ontological transition of resilience thinking from an equilibrist, engineering-dominated concept to a more evolutionary perception driven by the system's theory, systemic adaptive capacity, transformability and preparedness [6]. In this approach, appreciation of geological risk lies in the implementation level, with metropolitan and municipal authorities.

One of the current initiatives representing the second approach is the ' 100 Resilient Cities Network' (100RC). 100RC was launched by the Rockefeller Foundation in 2014 in an attempt to "help cities around the world become more resilient to the physical, social and economic challenges that are a growing part of the 21st century" [7]. The overall aspiration of the Network is to make citizens and infrastructure more resilient to disruptive events, including chronic stresses (e.g., resource shortages, inefficient public transportation, unemployment) and acute shocks (e.g., natural disasters, disease outbreaks, political instability).

The operational process for the cities joining 100RC is divided into three phases. The first phase includes the understanding and categorisation of the city's resilience components and the identification of the most pressing shocks and stresses. Its outcome is the Preliminary Resilience Assessment (PRA). The second phase emphasises the preparation of the Resilience Strategy (RS) based on the discoveries determined in the PRA; finally, the implementation phase operationalises the RS and Action Plan in a set period of time.

The Network understands urban resilience as "the capacity of individuals, communities, institutions, businesses, and systems within a city to survive, adapt, and grow no matter what kinds of chronic stresses and acute shocks they experience" [8]. Moreover, it concurrently recognises the need for multi-stakeholder mobilisation and coordination at a wide array of spatial scales, so as to inform the decision-making process [9]. This challenge presupposes the overcoming of operational silo-mentality within the municipalities [10], the adopting of a horizontal management approach and the appreciation of interdependencies with external partners [11].

The theoretical framework upon which the project was constructed, the 'City Resilience Framework' (CRF), is a complex scheme of qualitative features, which divided urban resilience into four categories (people, place, organisation and knowledge), 12 goals and associated key indicators, 54 sub-indicators and 130-150 variables. The CRF, according to its designers, is primarily directed at municipal and metropolitan governments and provides an evidence-based articulation of the fundamental attributes constituting a resilient city and how they can be achieved [8]. The key recommendation in CRF is to look at the urban system holistically, i.e., understanding the systems that make up the city and the interdependencies and risks they may face. One of the key interdependencies where this principle applies the most is recalled by CRF under the category "place": goal 7, "reduced exposure and fragility," which loosely refers to geological risks, aiming at the reduction of urban systems' exposure and vulnerability to natural hazards [8].

Nevertheless, since resilience comprehension within 100RC is undeniably content-related, integration of geological risk into Resilience Strategies depends solely on the prioritising of shocks and stresses by each local authority. Consequently, as political criteria are applied to the preparation of the Resilience Strategy, implementation challenges related to the appreciation of geological risk emerge. 
As geohazards occur less frequently than election cycles, the impact of geological risk is unlikely to influence election results; hence, geohazards are often treated as 'black swan' events (see [12]) and are marginalized in the design of Resilience Strategies. The understanding of such implementation challenges for Resilience Strategies, when referring to geological risk, is the main focus of this article.

In order to explore this narrative, we present the results of our investigation in Thessaloniki, Greece. Thessaloniki joined the 100RC network, along with 32 other cities, in 2014. Despite having wide experience of natural, economic, social and geopolitical disruptions throughout its long history, this project was the first clear manifestation of a dedicated resilience policy for the city. Through this participation, the local authorities expected to obtain assistance in familiarising themselves with the operationalisation of urban resilience, access to both substantial funding and appropriate tools to begin nurturing resilient thinking and leverage exchange of knowledge, information and resources with cities facing similar types of acute shocks.

After completing the first phase of implementation in late 2015 with the publication of the Preliminary Resilience Assessment (PRA) report, Thessaloniki released on 30 March 2017 its "Resilience Strategy 2030" (RS) [13,14]. The RS sets strategic goals, objectives and actions in an attempt to assist in the development of a holistic framework of urban governance, focusing on restructuring the current operational models in the Metropolitan Area, enhancing the city's attractiveness and extroversion, and facilitating the everyday life of citizens.

With regard to geological risk, Objective H of Goal 3 the RS sets out the vision for "Local risk reduction and risk management systems" through better coordination between the municipal administration processes, prioritisation of the investments in critical infrastructure (e.g., roads) and improvement of regional drainage and rain water management systems. However, except for a few mentions of local topography and past experiences of natural hazards that affected the city, there is not a clear holistic framework for tackling urban geohazards and integrating geological and geomorphological conditions into risk reduction, eventually reflecting the RS implementation challenges [15].

To highlight these implementation challenges, we focus on the two specific geohazards, earthquakes and surface flooding, that were identified by the PRA as the most imminent acute shocks for the city. We first review the geological context and natural hazard susceptibility at regional to city levels. Then, we present the results of our analysis at neighbourhood level in Acheiropoietos neighbourhood, within the historic centre of the city, and the village of Perea in Thermaikos Municipality.

\section{Materials and Methods}

\subsection{Methodological Approach}

This article addresses the implementation challenges for Resilience Strategies to consider geological risk. The basic idea of our approach follows the hypothesis that certain resilience policies tend to overlook geological risk, causing policy implementation gaps. We conceptualise geological risk following the classic definition: Risk $=$ hazard $x$ vulnerability $\times$ exposure. In our case, hazards are represented by the most imminent acute shocks identified for Thessaloniki by the PRA, namely earthquakes and surface flooding, vulnerability by the underlying geology and urban geomorphology of the urban settings, and exposure by the configuration and condition of the built environment.

Thus, we re-examined the geology and physical environment of the whole region covered by the official boundaries of the Metropolitan Area of Thessaloniki (Figure 1) and identified, at city-scale level, the lithological, superficial geology and topographical differences and gradients that make the city susceptible to the geohazards mentioned in the PRA and RS. We also reviewed the history of natural hazard events that affected the city as per the records in the Greek national catalogues of hazard events. Table A1 in the Appendix section lists the spatial data that we used and their sources. Our major outcome was the identification of the main areas presenting the geological conditions most 
predisposing to susceptibility to seismic hazards and surface flooding. Full results are presented in Sections 3.1 and 3.2, respectively.

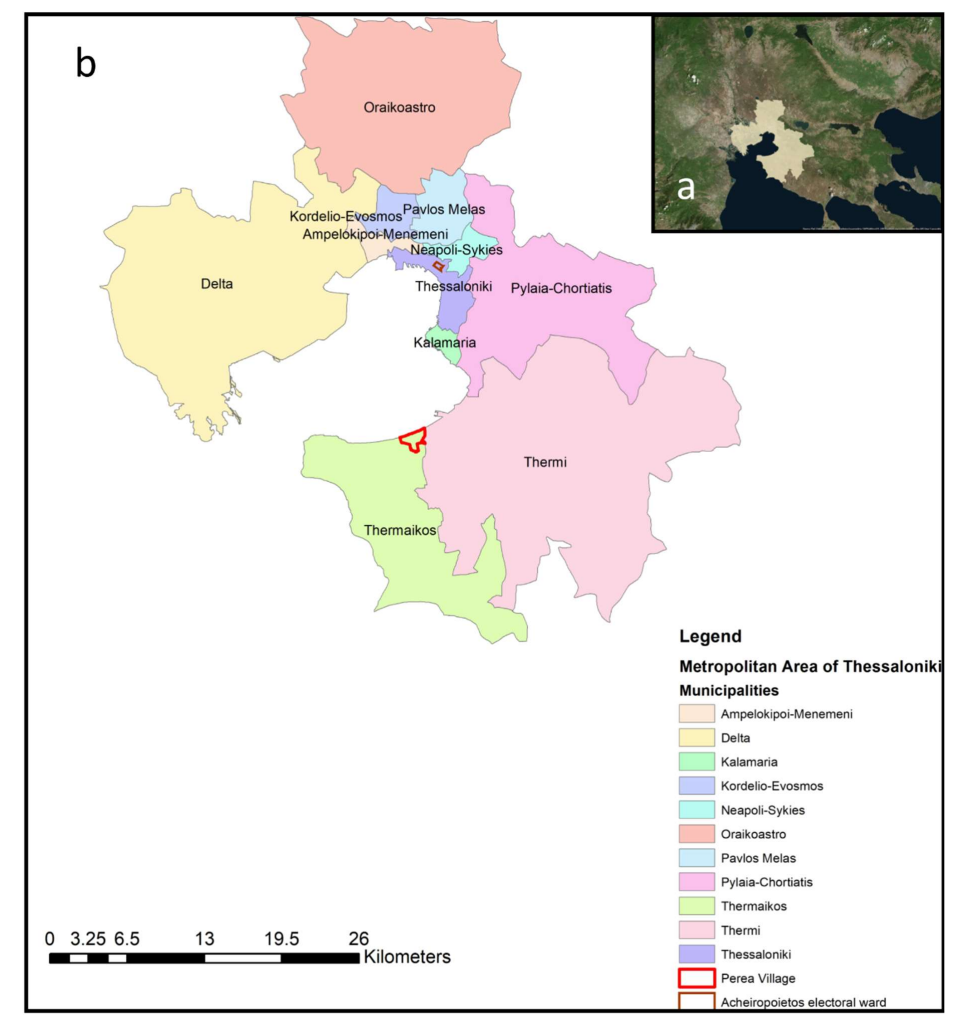

Figure 1. (a) Geographic location of the Metropolitan Area of Thessaloniki; (b) the 11 municipalities with indication (red boxes) of the location of Acheiropoietos and Thermaikos neighbourhoods.

Furthermore, we investigated the spatial intersection between the hazardous geological and topographic conditions and the characteristics of the built environment that could exacerbate the impact of earthquakes and floods. In particular, we reviewed the historical urbanisation of Thessaloniki, paying significant attention to deposits and stratifications in the older city centre, as well as the last-century urban sprawl in the newest municipalities. This was performed by combining different sources of information (see also Table A1 for details and data sources):

- location, footprint and use of buildings, roads and infrastructure as per the official datasets available from the city data portal, Open Street Maps and Copernicus Land Monitoring Service Urban Atlas;

- thickness and distribution of the anthropogenic deposits published in the specialist literature, particularly by Makedon et al. [16] (but others as well), which was also our main reference for the spatial classification of buildings in the city centre by building code, damage mapped after the major earthquake event occurred in 1978 and thickness of the underlying deposits;

- location and extent of new urban development as evidenced by analysing the time series of high-resolution satellite optical imagery (2003-2017) available in Google Earth and Bing Maps.

Afterwards, we examined the extent to which Thessaloniki's RS considers geological risk. Therefore, we examined the urban resilience policy documents published by the Municipality of Thessaloniki, with special emphasis on the Preliminary Resilience Assessment (PRA) and the" Resilience Strategy 2030"-(RS) [13,14]. This process assisted us in identifying the major implementation challenges for the RS, connected to geological risk, which we are describing to a greater extent in the Discussion section. Shortly, we derived the following points from this revision:

- the geohazards recognised by the Municipality as key sources of shocks for the city; 
- the indication of the components of the city urban environment and land use that raise major concerns for their potential role (either beneficial or detrimental) on management during emergencies and towards risk reduction;

- the aspiration of the city, its vision and planned actions to achieve the goal of reducing risk.

Figure 2 depicts schematically our conceptual research approach.

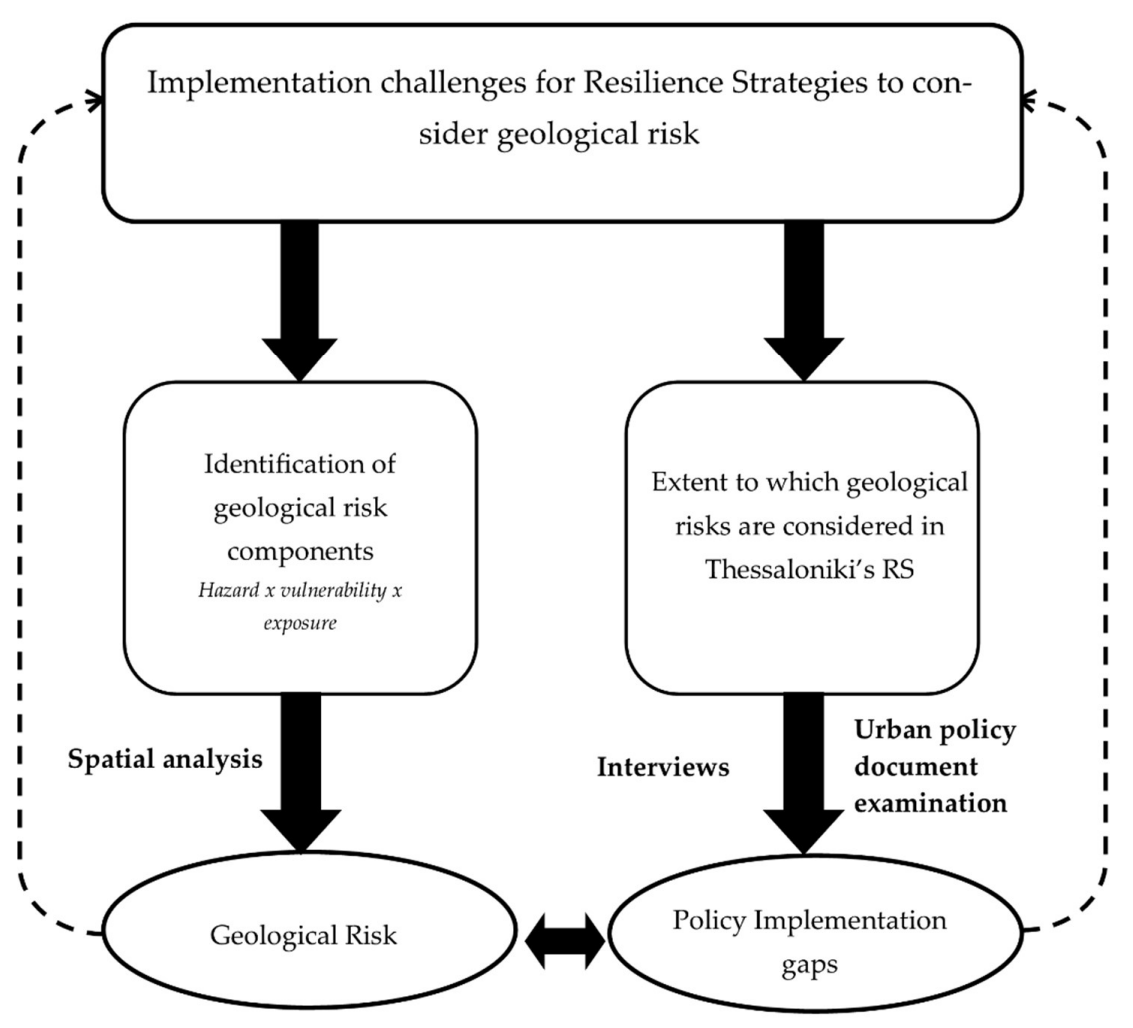

Figure 2. Research approach.

A base-map of Thessaloniki's surface and subsurface environment was also created. The geological map of the Thessaloniki Metropolitan Area was digitised, as well as the engineering geology map of the city and maps of geomorphological interest, such as urban fills in the historic centre of the city and combined it with other publicly available datasets producing a visual representation of the city's Metropolitan Area. Administrative criteria were applied in choosing our two focus areas, i.e., an electoral ward in the historic centre of the city and a municipality in the southern side of the metropolitan area. Both areas have had disastrous experiences from earthquakes and surface flooding respectfully, which have been largely induced by the unregulated urbanisation and poor integration of geological input in planning policies.

To perform this qualitative spatial analysis, we combined the abovementioned data to create maps of the metropolitan area in ArcGIS and QGIS, eventually focusing on the following two neighbourhoods: Acheiropoietos in the city centre and Perea in the Thermaikos Municipality. In the case of Acheiropoietos we measured the building density of the residential building blocks using the floor area ratio index (FAR). FAR is defined as the ratio of the total square meters of a building divided by the total square meter of the lot where the building is located. In principal, higher FAR numbers tend to indicate more dense urban areas. In this way, the index is accounting for the whole total floor area of a building and not only for its spatial footprint. We have also added the mean number of floor as well as building heights in order to avoid potential misinterpretations. Furthermore, we calculated the mean and minimum distance of the building blocks from urban free spaces, we used the centroids of the respective free-space lots and building blocks. The process we followed for our spatial data analysis is presented in Figure 3. 
As a last step, we complemented our spatial analysis with data collected from interviews with city officials, including Thessaloniki's Chief Resilience Officer and the members of the Municipality's Resilience Office. We have conducted three semi-structured interviews with city officials which lasted for approximately one hour each; two of them were face-to face while one was via teleconference. The topics we explored had to do with the process of designing the RS, the main problems faced throughout this process, the major outcomes that came out of the PRA, the rationale behind decision on the final focus areas as well as implementation challenges that may emerge. Later in the article we report some extracts from these interviews, to substantiate the discussion of the key outcomes of our research.

The structure of the article follows our conceptual research approach. In Section 2.2 and after a brief introduction of the city's participation in the 100RC network, we are presenting the hazards (earthquakes and surface flooding) threatening Thessaloniki, while in Sections 3.1 and 3.2 we are exploring geological vulnerability and exposure of the built environment to these hazards, so as to highlight the geological risk the city is facing, and the policy implementation gaps in the RS. Finally, in the Section 4 we identify the main implementation challenges and come up with recommendations for potential improvement of the current RS.

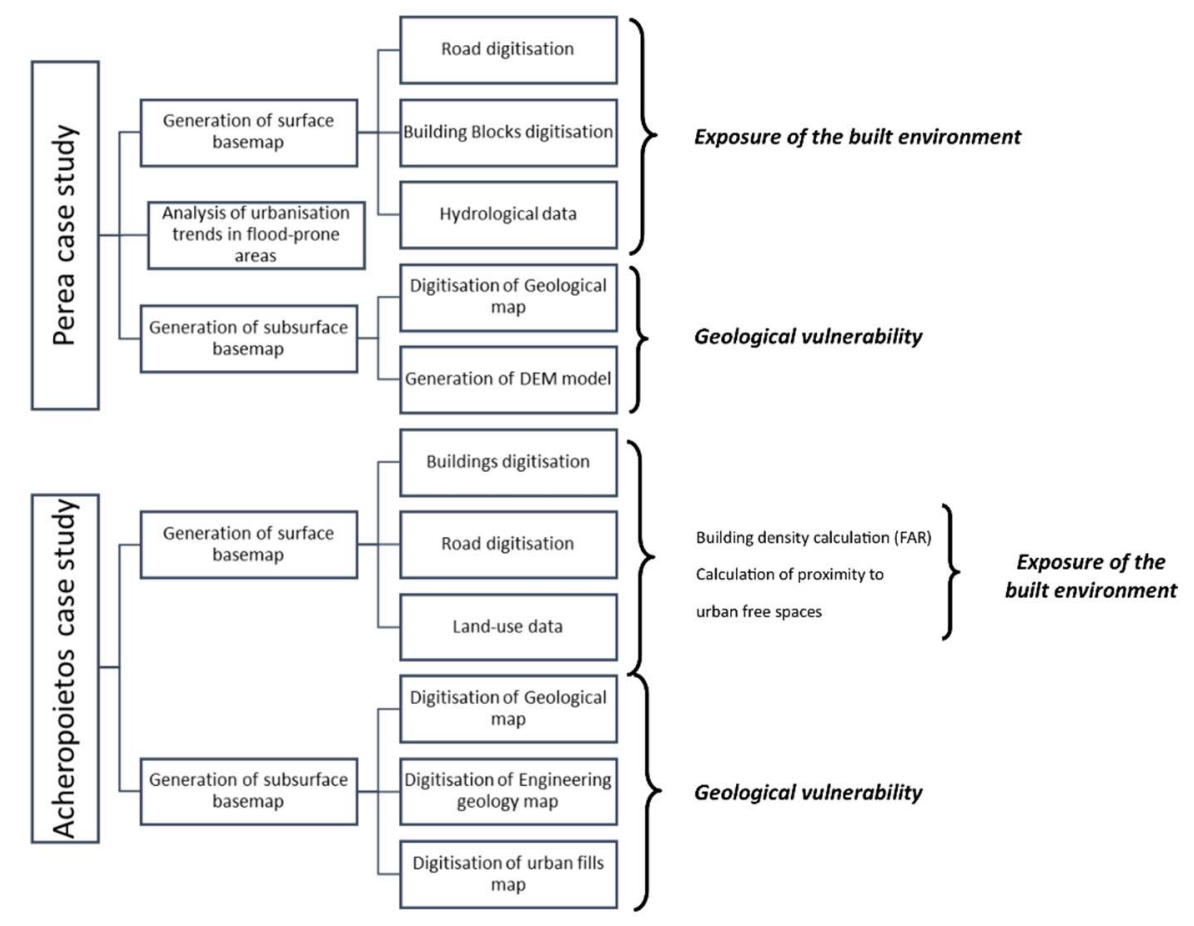

Figure 3. Spatial data analysis process.

\subsection{Presentation of the Case Study}

\subsubsection{Thessaloniki's PRA and RS}

The participation of Thessaloniki in the 100RC network was itself a great challenge for the city. The lack of familiarity with resilience principles and policies has arguably been the most important challenge for Thessaloniki's RS, as new concepts and principles introduced for the first time to local officials, needed to be incorporated to the municipality's 'modus operandi'. Thus, the first goal of the RS was to clarify the city's strengths and weaknesses, identify potential opportunities and threats and create an effective and viable vision for the city.

It is safe to say that this endeavour has been largely successful, as for the first time more than 40 organisations and 2000 citizens participated in the resilience dialogue, partially shaping the base for its implementation [14]. This wide multi-stakeholder engagement generates a new reality for the city 
achieving, to a certain extent, a first layer of resilience building, by creating capacities absent in the past $[17,18]$. Moreover, it provides a roadmap for guiding developmental activities in the city, thus becoming an invaluable document governing Thessaloniki's strategic urban planning.

Weighting its acute impact and broad influence, the PRA identifies earthquakes and surface flooding at the top of the five shocks or stresses for the city. This also comes from a review of the major shocks, either natural or human-induced, occurred in the modern history of Thessaloniki. In this regard, Figure 4 is a modified version of the Thessaloniki Resilience Timeline that is published in the PRA [13], through which we want to highlight which of the shocks are recognised as having generated either positive or negative impacts on the urban environment, as well as having shaped city policies of disaster management and risk reduction.

This, in a sense, seems to confirm that the city has already a history of positive relationships between hazards and urban planning and design, despite the fact that this process is not always constant or linear. For example, since the 1978 earthquake the seismic code in Greece has been changed and upgraded several times [16,19]. The most important reform was the release of the New Seismic Code for Building Structures in 1984, which was introduced after the earthquakes in Thessaloniki (1978) and Alkionides (Athens) 1981, and divided Greece into three different seismic zones, with more tightening the regulatory framework for new constructions around the country. Thessaloniki was included in Zone II.

However, this not necessarily brought to retrofit all the existing buildings and infrastructure (e.g., also due to the lack of investments). In this regard, both the PRA and RS mention the ageing building stock and housing infrastructure among the stresses directly related to the current economic condition and past urban development, alongside dense urban structure with limited open and green spaces.

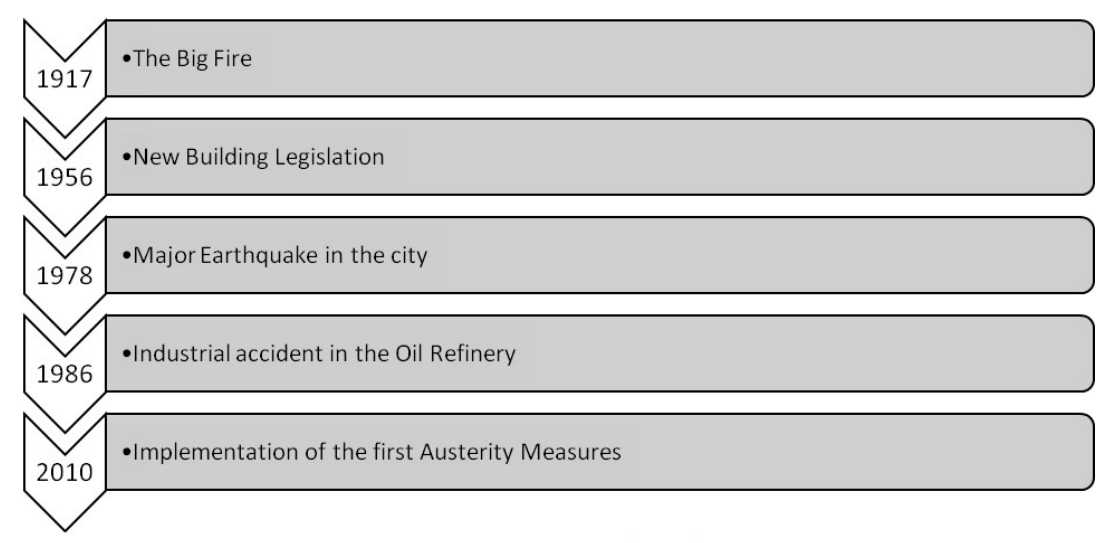

Figure 4. Thessaloniki hazard timeline (modified from [13]).

\subsubsection{Seismic Susceptibility}

Thessaloniki was founded in $315 \mathrm{BC}$ and has since its founding has faced continuous urbanisation. Due to its geographical location the city has historically played a dominant role as a focal trading, exchange, transportation, multinational and cultural point at both a national and an international level. Its port is the second biggest in Greece and among the most important in the Mediterranean, while the HELEXPO International Exhibition Centre plays a predominant role in the business community in southeastern Europe. The wide seafront is one of the most significant assets of the city, especially after its renovation was completed in 2011, where continuous pedestrian and bicycle paths intermingle with a series of consecutive thematic gardens [20].

Thessaloniki's current urban area ranges in a NW-SE direction between the hills of Oreokastro and the mount of Chortiatis (Figure 1a). In parallel, the Metropolitan Area of the city extends further in the west up to Loudias River and south, surrounding the whole areas around the Thermaikos gulf. From an administrative perspective and following the last administrative reform of the country in 
2011 (Kallikratis Plan), the metropolitan area consists of 11 municipalities, with the Municipality of Thessaloniki holding the most central position among them (Figure 1b). The Municipality's population is 324,766, while the Metropolitan Area accounts for around 1.12 million residents (2011 census).

From a geomorphological perspective, the city's elevation starts at sea level and reaches almost $950 \mathrm{~m}$ around Chortiatis, while within the urban area it does not exceed $150 \mathrm{~m}$ with smooth ascents [16]. This morphology favours the outburst of surface flooding phenomena to specific downstream sites in the Metropolitan Area. For instance, the existence of streams and gullies in the relatively low elevation areas and in close proximity to residential settlements in the municipality of Thermaikos has played a central role in the accumulation and channelization of the excess of water during heavy rainfall events (see Section 3.2). Similar issues have been identified in the Municipality of Delta in the western part of the Metropolitan Area, where three different rivers flow in (see [21]).

The geological map of the Metropolitan Area demonstrates the heterogeneity of lithologies upon which the city has developed throughout the years (Figure 5a). Holocene deposits, red clay and sandstone marl dominate the southern and western parts, while the higher altitudes of the eastern part, the Chortiatis mount rises, are primarily covered by various metamorphic formations. Thessaloniki's historic centre in particular, is located in the junction of three different lithologies, each characterised by different depth (Figure 5a,b). Moreover, after many years of continuous inhabitancy, the historic centre consists of large areas of filled ground with different characteristics and attributes [16]. In general, deeper urban fills are much more prone to earthquake damage [22], and in Thessaloniki's case they exceed the average fills of similar size and historical background cities reaching even $15 \mathrm{~m}$ within the limits of the ancient city walls in Zone II (Figure 6). Makedon et al. [16] identify this layer as the most prone to building damage from a 100-year earthquake event.

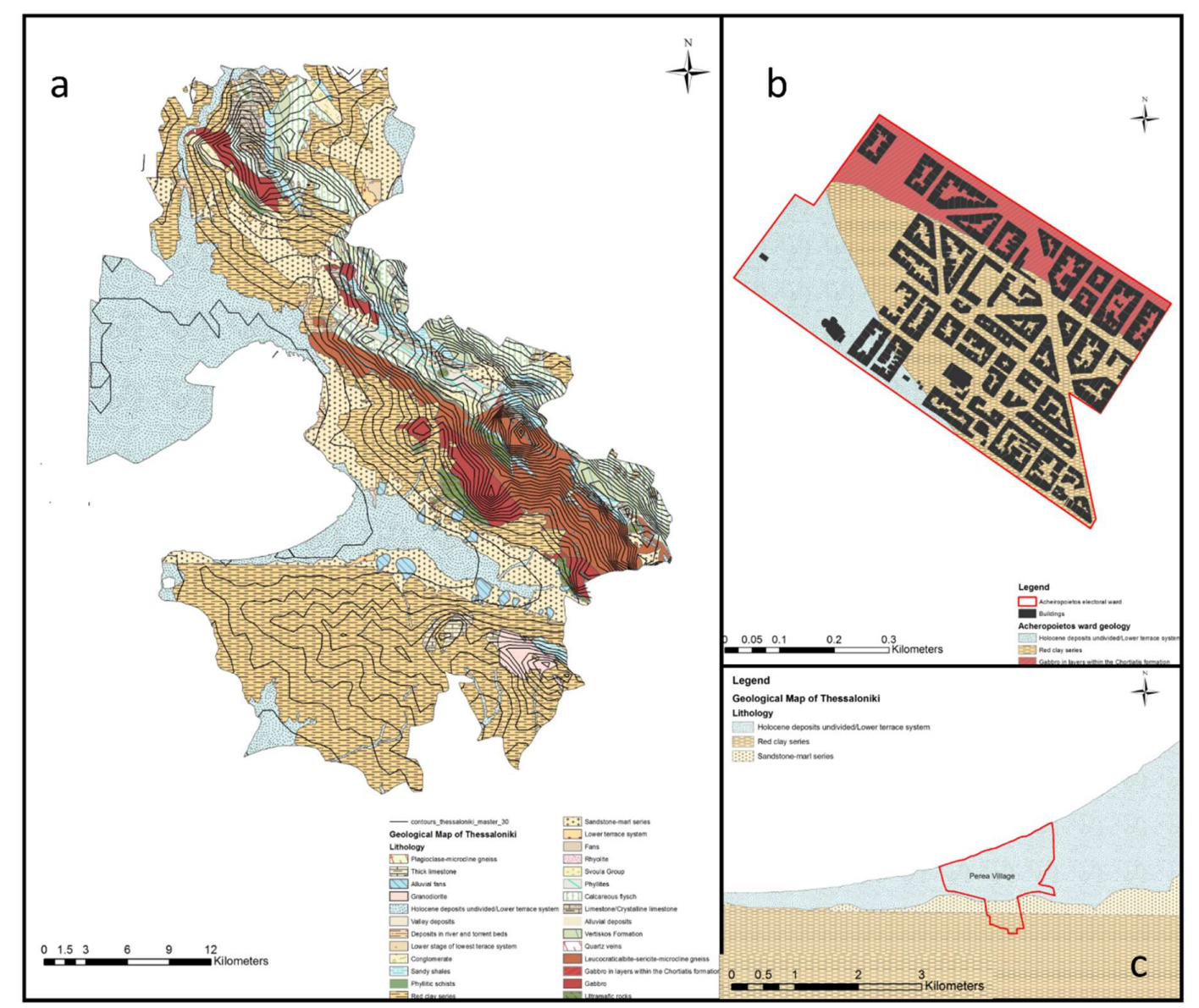

Figure 5. (a) Geological map of the Metropolitan Area of Thessaloniki with 300 m contours. (b) Bedrock geology in Acheiropoietos; (c) bedrock geology in Thermaikos neighbourhoods. 

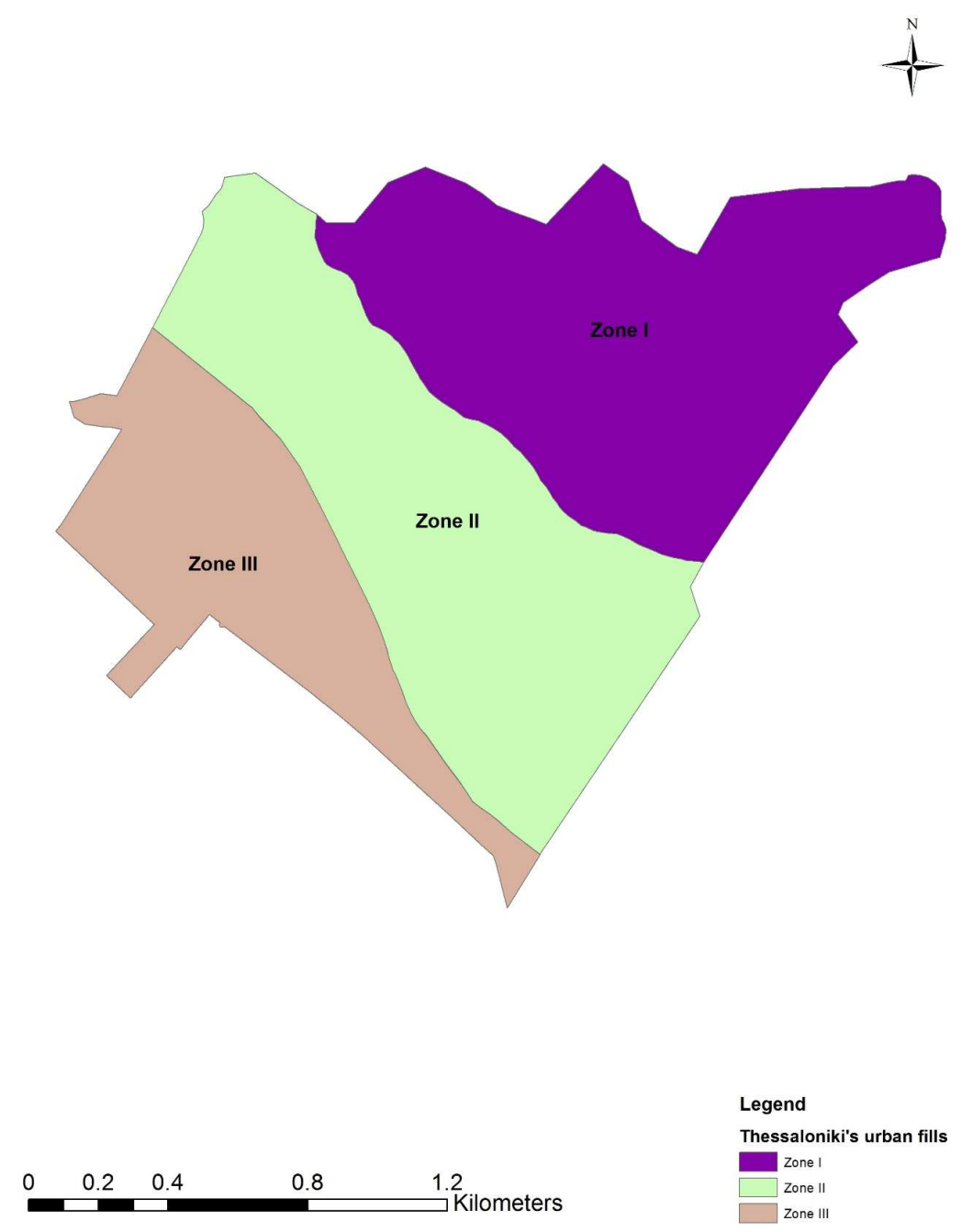

Figure 6. Map of urban fill thickness underneath the historic city centre (modified from [16]).

This geological heterogeneity produces divergent geographies susceptible to distinct types of geohazards. Thus, the Holocene deposits in Delta Municipality and Perea Region (Figure 5c) lead to land subsidence whenever farming activities and urban development require high levels of groundwater abstraction [21,23]. Furthermore, during the last decade, continuous pumping has led to the exposure of low-lying areas to surface flooding, due to the recovering of groundwater levels and constrained drainage of the water flow as a result of the deeper topography [23].

From a tectonic perspective, Thessaloniki belongs to the Circum-Rhodope zone, which traverses the central part of Macedonia in northern Greece at a general NW-SE direction and lies between Axios zone and the Serbomacedonian massive (Figure 7). Even though Thessaloniki is partly located in the least active seismic zone (Axios), the Serbomacedonian massive lying nearby is a geotectonic zone presenting very high levels of seismicity [16]; as a consequence, the city has sustained numerous events of medium or higher repercussions. Apart from the 1978 earthquake, which was the highest of a series of approximately 100 earthquakes, seismic activity in Thessaloniki is still more than apparent, with several light, moderate and strong events occurring regularly. 


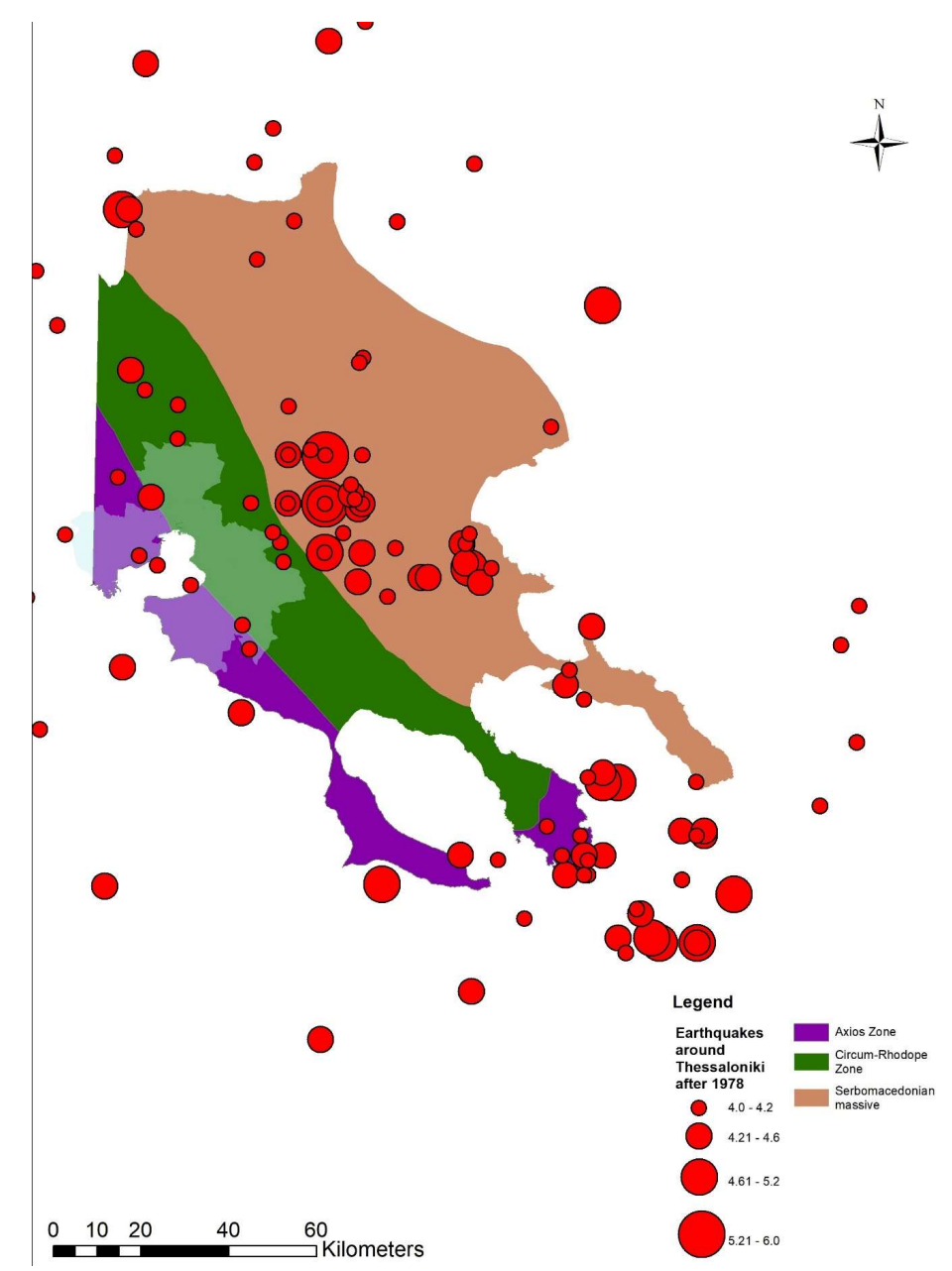

Figure 7. Earthquakes over 4.0 Richter magnitude around Thessaloniki Metropolitan Area after 1978 and the geotectonic zones of Northern Greece.

The current seismic susceptibility of Thessaloniki's built environment to damage has its roots in past construction practices. The city suffered wide structural damage during the 1978 earthquake from differential settlement on soft sediments, particularly within its historic district [24]. In parallel, the absence of an organised and robust planning regulatory framework contributed in dense, unregulated and earthquake vulnerable urban planning. This absence has led to urban expansion in hazard-prone areas, particularly within the city centre (no detailed seismic micro-zonation), lack of open public spaces (potential assembly areas during evacuations) and high probability of cascading effect due to the proximity of buildings to one another.

The building stock of the city consists primarily of Reinforced Concrete $(\mathrm{R} / \mathrm{C})$ and Unreinforced Masonry (URM) buildings designed according to old codes, including pre-1959, or 'pre-code' buildings whose performance was found to be very similar to that of low-code ones, as reported in [25]. Additionally, the city accommodates 340 impressive historic monuments from the Roman, Ottoman and more accurately Byzantine period. Most of them are religious settings (i.e., churches, mosques) and they are predominantly located within the Municipality of Thessaloniki.

The 1978 earthquake, which resulted in the death of 49 people, the collapse of a nine-storey R/C building and the damage beyond repair of $4.5 \%$ of the city's building stock [25], induced a massive reform of the building codes, especially within the historic centre of the city [24]. Yet, despite this reform as mentioned, the majority of buildings in the historic centre are 6-9-storey residential R/C or URM constructions either designed or erected following the old code of 1959, presenting similar engineering performance $[16,24]$. The historic centre has been predominantly built with the use of $\mathrm{R} / \mathrm{C}$ 
as a result of the Great Fire of 1917 and has experienced very low reconstruction rates after the 1978 earthquake [26].

.It is worth noting that rubble from the 1978 seismic damage has contributed, along with other geomorphological factors, to the formation of current urban fills. Based on an analysis of the composition of Thessaloniki's urban fills, Makedon et al. [16] projected that a seismic event could still inflict substantial damage in the historic centre.

The performance of Thessaloniki's building stock in case of an earthquake has been widely analysed in the literature, via models, risk assessments and scenario-based methodologies [24-27]. It is beyond the scope of this article to analyse in detail the assessment methods used in the cited studies; however, their common conclusion is that the city, and particularly its historic centre, would be severely impacted by an earthquake similar to the one that occurred in 1978. Around $10-12 \%$ of the current buildings located within the Municipality of Thessaloniki are expected to suffer severe losses, while the estimated costs of repair for direct damage reach approximately $€ 1,500,000,000$ [26]. Moreover, indirect economic and cultural blows are expected to be inflicted by damage to historic monuments, which serve as tourist sites and preserve Thessaloniki's urban identity.

In addition to building codes, urban design following the typical approach favoured by other Greek cities plays a key role in Thessaloniki's exposure to catastrophic damage in case of seismic events. The historic centre and inner zones are characterised by high densities of buildings, a lack of public open spaces and green spaces, and insufficient parking spaces [28]. Narrow streets and unregulated urban development constrain the ability of local and national authorities to design appropriate evacuation routes in case of emergency, impeding the role of civil defence in planning disaster management. The lack of open spaces (potential assembly areas) and the ageing building stock, as highlighted in the PRA, represent major resilience concerns for the city; we explore such concerns below, unaddressed by the RS, through our case study of the Acheiropoietos electoral ward.

\subsubsection{Surface/Groundwater Flooding}

The review of Greek national catalogues of natural hazard events and scientific literature on nation-wide flood hazard and risk assessment (see Table A1) confirms that the whole prefecture of Thessaloniki is highly susceptible to flash floods. From a historical perspective, Diakakis et al. [29] analysed the spatial distribution of the flood events recorded in 1880-2010 and found that the Metropolitan Area of Thessaloniki is second in Greece after Athens, for either total number of events per prefecture or number normalized per $100 \mathrm{~km}^{2}$. The evidence for an increased clustering of flood events is also confirmed by the study by Papagiannaki et al. [30], which found around the Thessaloniki area one of the highest frequencies of high-impact weather events, with a total of 27 events in the decade 2001-2011, of which 71\% were flash floods. Indeed, across the Metropolitan Area of Thessaloniki, severe floods occurred on 8 October 2006 and 21 September 2011 (both events were also studied by Nikolaidou et al. [31] with the aid of Earth Observation data from satellites), 16 July 2014, 7 September 2016 and 11 May 2018.

Flash floods normally occur as a result of substantial precipitation in areas with limited ground absorption capacity; they may also cause cascading urban geohazards, such as landslides, sinkholes, and erosion [32]. Moreover, they are extremely complex and unexpected hazardous phenomena, which take place in short temporal periods and thus are very challenging to predict [33]. As global climate change is expected to increase the frequency of extreme weather incidences, there are more compelling reasons for local authorities to focus on addressing their impact.

In Thessaloniki, geology can also favour surface flooding. Quaternary lower terrace alluvial deposits and red clay, especially in the southern and eastern parts (Figure 5a,c), which tend to be impermeable, are susceptible to runoff water and inevitably to the enhancement of the potential for serious flooding downstream, during heavy rainfall events. This runoff water afterwards concentrates in ravines and streams, forms larger volumes of water and frequently joins in a fast-flowing mass of water and debris. 


\section{Results}

\subsection{The Acheiropoietos Electoral Ward Case Study}

\subsubsection{Geological Vulnerability}

The first case study of our analysis is the electoral ward of Acheiropoietos. Acheiropoietos neighbourhood is located within Thessaloniki's Municipal Unit A and is a typical example of an earthquake vulnerable neighbourhood within Thessaloniki's historic centre. As mentioned before, Thessaloniki is an area of high seismicity, thus inherently vulnerable to earthquake events.

The neighbourhood stands upon three different types of lithology (Figure 5b): Holocene clay-sand pebble alluvial Deposits (SE), sandstone marl (CE) and the superficial, metamorphic gneiss, epigneiss and green schists and of the Chortiatis magmatic suite. Anastasiadis, Raptakis, \& Pitilakis [34] include Acheiropoietos among the areas most prone to damage from an earthquake with intensity ranging from 6.5 to more than 8 (Id, Ie and If). Factors that can act detrimentally in such circumstances include: slight local topography, large inclination of the buildings with regard to the top of the bedrock, the presence of superficial artificial fills with great thickness (up to $13 \mathrm{~m}$ ) and the strong lateral variations regarding seismic and geophysical parameters of the high plasticity of the clayey formations. Additionally, the low engineering behaviour (i.e., the capacity of the ground to bear construction and buildings) of loose alluvial deposits in conjunction with the unstable metamorphic formations and the thick layer of historical fills and embankments lying between the surface and bedrock geology produce a complex, heterogeneous geological environment with unpredictable behaviour in turbulent conditions.

Finally, the presence of thick urban fill below the study area (see Figure 6) exacerbates its earthquake vulnerability. Acheiropoietos is located within the urban fill Zone II, which has been identified by Makedon et al. [16] as the deepest and most prone to damage from a 100-year earthquake event. The high damage ratio of this historic fill embankment is also closely correlated with the current condition of the building stock.

\subsubsection{Exposure of the Built Environment}

Acheiropoietos is a residential area characterised by dense building blocks of similar typology (6-8-storey buildings), the majority of which are used as general housing, while some blocks accommodate educational facilities, and more specifically schools (Figure 8a). The built environment also includes some important historical monuments and buildings, such as Thessaloniki's Roman Forum, the 11th-century CE Byzantine Church and an Ottoman Hammam, which underwent extensive restoration after the earthquake in 1978. This neighbourhood was almost entirely built under the low building code (pre-1984) [24] and provides an example of the damage caused by the 1978 earthquake [27]. In more detail, out of the 440 residential buildings within the neighbourhood more than $80 \%$ have been built before under the low building code (pre-1984), while, based on Papadopoulou et al. [35], the number of buildings within the Acheiropoietos neighbourhood that had experienced moderate or serious structural damage is around $18 \%$, and thus higher than the city's overall ratio of building stock affected in Thessaloniki.

High building density, in conjunction with increased building heights and the proximity of buildings to one another, increase the exposure of the built environment to seismic events. Acheiropoietos has a mean building density (FAR) of 3.37, a number similar to most of the neighbourhoods within the historic centre of the city and higher than the other parts of the city [36]. Figure 9a,b demonstrates the high building density and number of floors of the building blocks within the study area. 


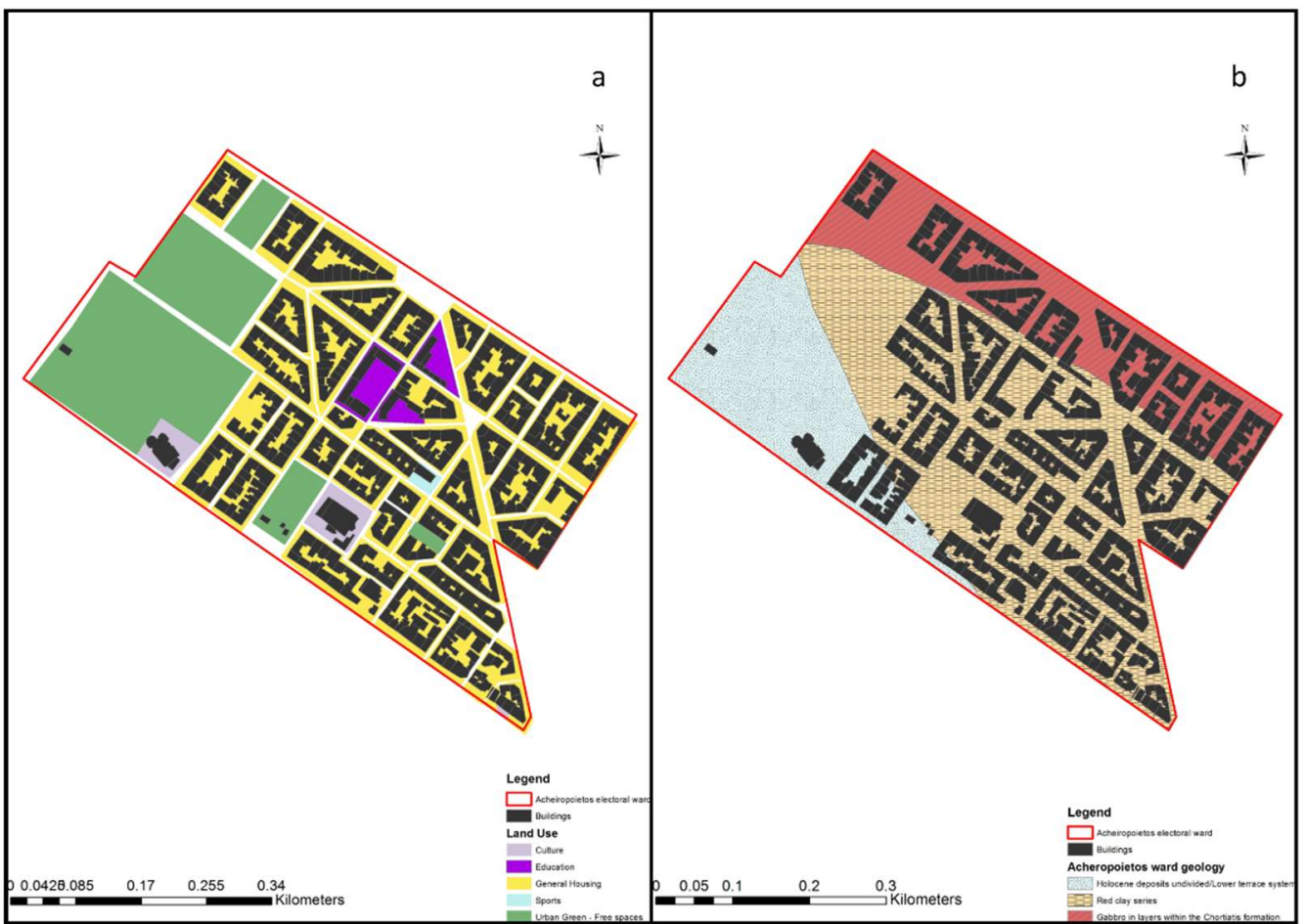

Figure 8. (a) Land use (building block level); (b) bedrock geology underneath the buildings in Acheiropoietos.

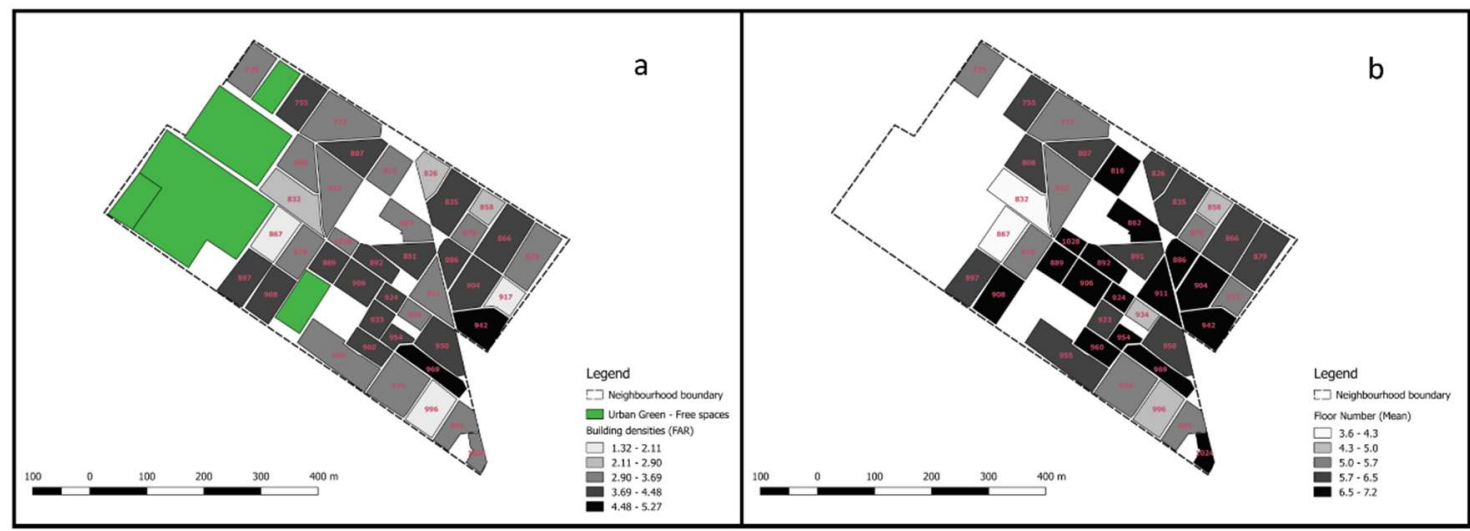

Figure 9. (a) Building densities and (b) floor numbers per residential block in Acheiropoietos neighbourhood.

Meanwhile, the mean value of building heights is also quite high, 6.07, a factor that, combined with the proximity of buildings mentioned above, could result in 'domino' collapse during an earthquake. 'Domino' collapses are one of the most significant reasons for major fatalities in urban earthquake events. Rubble accumulation from building collapses can obstruct narrow streets during evacuation and restrict the access of emergency responders to the site, thus adding to the abovementioned predisposing factors and the lack of open collection points connected via wide and straight evacuation routes. In the Acheiropoietos neighbourhood, even though there is a greater presence of open spaces than in other urban neighbourhoods of the historic centre ( $26 \%$ of the total land coverage), some of the building blocks with very high building densities (i.e., 866, 879, or 1024) are more than $350 \mathrm{~m}$ away from them. This fact, in conjunction with the very narrow local streets in the neighbourhood $(<4 \mathrm{~m})$, would impede large-scale evacuations in the case of earthquake disasters [37].

Table 1 presents the mean and minimum distance of each residential block from a free space within the Acheiropoietos neighbourhood. 
Table 1. Urban features and characteristics of the Acheiropoietos neighbourhood.

\begin{tabular}{|c|c|c|c|c|c|c|}
\hline $\begin{array}{l}\text { Building } \\
\text { Block }\end{array}$ & $\begin{array}{l}\text { Number of } \\
\text { Floors (Mean) }\end{array}$ & $\begin{array}{c}\text { Building } \\
\text { Density (FAR) }\end{array}$ & $\begin{array}{l}\text { Building Height } \\
\text { (Mean) (m) }\end{array}$ & $\begin{array}{l}\text { Area } \\
\left(\mathrm{m}^{2}\right)\end{array}$ & $\begin{array}{l}\text { Mean Distance from } \\
\text { Free Space (m) }\end{array}$ & $\begin{array}{l}\text { Minimum Distance } \\
\text { from Free Space (m) }\end{array}$ \\
\hline 725 & 5.50 & 3.08 & 15.40 & 4157.27 & 229.03 & 51.98 \\
\hline 755 & 6.45 & 3.72 & 18.06 & 4267.51 & 223.39 & 52.36 \\
\hline 772 & 5.59 & 3.07 & 15.65 & 7436.36 & 260.04 & 127.44 \\
\hline 807 & 6.38 & 4.04 & 17.86 & 4226.22 & 272.35 & 183.40 \\
\hline 808 & 5.82 & 3.38 & 16.30 & 4144.63 & 199.22 & 120.05 \\
\hline 816 & 6.67 & 3.44 & 18.68 & 3704.44 & 317.25 & 247.30 \\
\hline 822 & 5.43 & 3.10 & 15.20 & 6474.97 & 238.77 & 191.95 \\
\hline 826 & 6.00 & 2.78 & 16.80 & 2799.39 & 380.67 & 310.23 \\
\hline 832 & 4.19 & 2.27 & 11.73 & 5616.51 & 194.60 & 147.41 \\
\hline 835 & 6.27 & 3.82 & 17.56 & 5908.81 & 414.50 & 313.56 \\
\hline 858 & 4.50 & 2.62 & 12.60 & 2129.89 & 472.53 & 362.05 \\
\hline 862 & 7.14 & 3.32 & 19.99 & 3554.42 & 347.24 & 228.20 \\
\hline 866 & 6.12 & 3.98 & 17.14 & 6200.24 & 508.38 & 370.42 \\
\hline 867 & 3.60 & 1.32 & 10.08 & 4272.53 & 193.33 & 127.04 \\
\hline 870 & 5.09 & 3.33 & 14.25 & 2288.76 & 449.53 & 316.06 \\
\hline 878 & 5.69 & 3.66 & 15.93 & 4021.97 & 221.81 & 86.59 \\
\hline 879 & 6.25 & 3.17 & 17.50 & 5584.88 & 560.68 & 410.32 \\
\hline 886 & 7.17 & 4.18 & 20.08 & 2649.88 & 431.18 & 271.32 \\
\hline 889 & 6.83 & 4.29 & 19.12 & 2767.56 & 256.89 & 82.19 \\
\hline 891 & 6.25 & 4.01 & 17.50 & 3922.29 & 364.38 & 203.68 \\
\hline 892 & 6.50 & 4.37 & 18.20 & 2542.18 & 318.44 & 145.54 \\
\hline 897 & 6.36 & 3.81 & 17.81 & 4715.72 & 216.32 & 110.05 \\
\hline 904 & 6.64 & 4.12 & 18.59 & 5166.53 & 478.42 & 300.28 \\
\hline 906 & 6.64 & 4.00 & 18.59 & 3789.76 & 308.07 & 103.82 \\
\hline 908 & 6.69 & 4.19 & 18.73 & 4486.10 & 238.70 & 57.32 \\
\hline 911 & 6.63 & 3.39 & 18.56 & 4130.45 & 422.39 & 229.71 \\
\hline 917 & 5.40 & 2.00 & 15.12 & 2548.11 & 536.24 & 355.72 \\
\hline 924 & 6.50 & 4.05 & 18.20 & 1454.69 & 364.04 & 155.29 \\
\hline 933 & 6.40 & 3.74 & 17.92 & 2305.83 & 365.00 & 133.99 \\
\hline 934 & 5.00 & 3.03 & 14.00 & 1698.38 & 411.23 & 197.18 \\
\hline 942 & 6.80 & 4.51 & 19.04 & 4387.58 & 517.39 & 315.02 \\
\hline 950 & 6.40 & 3.93 & 17.92 & 4924.47 & 478.83 & 256.03 \\
\hline 954 & 6.67 & 4.47 & 18.68 & 1340.47 & 408.04 & 174.84 \\
\hline 955 & 6.36 & 3.23 & 17.81 & 7245.13 & 364.44 & 112.58 \\
\hline 960 & 6.67 & 3.96 & 18.68 & 2578.19 & 386.51 & 141.21 \\
\hline 969 & 7.14 & 5.27 & 19.99 & 3348.01 & 490.67 & 256.61 \\
\hline 974 & 5.29 & 2.94 & 14.81 & 6592.56 & 468.36 & 222.92 \\
\hline 995 & 5.47 & 3.19 & 15.32 & 3349.77 & 587.30 & 346.52 \\
\hline 996 & 4.89 & 2.00 & 13.69 & 4585.28 & 535.98 & 293.22 \\
\hline 1024 & 6.60 & 3.39 & 18.48 & 1558.93 & 644.60 & 403.41 \\
\hline 1028 & 7.00 & 3.16 & 19.60 & 1278.08 & 263.20 & 126.92 \\
\hline
\end{tabular}

Source: Processed by the authors. (Building heights have been calculated as number of floors $\times 2.80 \mathrm{~m}$.)

Summing up, Thessaloniki's geological risk of earthquakes, particularly when referring to its historic centre, is clearly visible in the Acheiropoietos case study. The component of vulnerability comprises high seismic activity, different layers of bedrock geology and thick and damage-prone urban fills, while exposure consists of ageing building stock, high building densities, difficult access to free spaces (potential assembly points in case of an earthquake) and the constant presence of vulnerable populations in local schools.

\subsubsection{Earthquakes in Thessaloniki's RS}

By analysing Thessaloniki's published documents from the participation in the 100RC network, we identified a struggle in the operationalisation of the PRA findings regarding seismic risk to Objectives and Actions in the RS. Although earthquake as a hazard is undoubtedly appreciated in both the PRA, where it was even identified as the most imminent acute shock for the city, and the RS, as the main topic of the newly established 'City Resilience Day' (Goal 2, Objective A, Action 6), no significant actions to deal with vulnerability and exposure of the built environment are included in the rest of the document.

In more detail, geomorphological vulnerability is not included in either document, demonstrating the absence of geological insight during the preparation of the RS, despite the collaboration with the Institute of Engineering Seismology and Earthquake Engineering (ITSAK) and the Aristotle University 
of Thessaloniki. Secondly, exposure of the built environment is not emphasised enough, despite the appreciation of the ageing building stock and the fragmentation and lack of open/free spaces.

Specifically, the only vaguely earthquake-related Actions come under Goal 3, Objective H: Local risk reduction and risk management systems; however, the focus of the proposed actions is generally put on natural hazards and not specifically on seismic risk management.

The main reasons for this absence and discontinuity among the PRA and the RS, according to city officials were:

1. A general understanding that the municipality should not be responsible for accounting for geological risk, as other institutions, such as the Decentralised Administration of Macedonia and Thrace or the Institute of Geology and Mineral Exploration, are more appropriate for this task.

2. The environment of the historic centre of the city is a retrofit environment and was perceived as having very little degree of adaptive opportunities, and thus technical measures were not explored further.

3. The fact that responsibility for policy, such as building codes, does not sit in the municipality.

4. Earthquake management was not categorized as a top-priority area for the design of the RS.

In a nutshell, the RS appreciates but does not adequately address Thessaloniki's urban geological risk to earthquakes. Moreover, there is an implementation gap between the PRA and the RS when it comes to earthquake management, as the proposed actions do not adequately reflect the outcomes of the assessment stage.

\subsection{The Thermaikos Municipality Case Study}

The Municipality of Thermaikos has been continuously affected by surface flooding, with the latest manifestation being the floods of September 2016 causing a fatality in the Michaniona area and extensive damage to public and private property [38]. Local authorities, in coordination with the national government, have undertaken the task of compensating the affected people-a financially unfortunate conjuncture for the whole country.

Analysing the undermining explanations for Thermaikos' geological vulnerability and exposure of its built environment to surface flooding, we realised that the most significant factors for this phenomenon are the physical geography and topography of the area and the extensive, semi-regulated urbanisation, which started around 25 years ago and worsened during the last decade.

The village of Perea is a demonstration case study, with interdependencies between at least two natural and one anthropogenic factors: local geology and topography; extent and location of urban development.

\subsubsection{Geological Vulnerability}

The underlying geology of the area is relatively homogeneous and includes two major geological units (Figure 5a,c): Neogene deposits outcropping at the areas with higher elevation towards the mainland, and Quaternary alluvial deposits in the plain area towards the coast [30]. The Neogene deposits consist of two main sequences, the upper sand and gravel sequence and the lower sandy marls-red clays sequence. At the same time, the Quaternary formations occupy the central part of the so-called Anthemountas basin [21,23], with increasing thickness towards the coast. According to Raspini et al. [21], the Quaternary formations, consisting of alternating layers of clastic and fine-grained sediments, create conditions favouring the development of an upper phreatic and several successive semi-confined aquifers, while the depth of coastline sediments reaches $140 \mathrm{~m}$.

Consequently, V-shaped, nearly parallel, ravines are formed, following the natural topographic gradient of the region down to the coastal plain, where recent urbanisation occurred as either new development or densification of the built environment. In addition, the impermeable Quaternary alluvial deposits, along with the increasingly limited absorption capacity of the urbanised physical 
ground due to the imperviousness of tarmac and concrete pavements, increase the possibility of runoff water concentration and the formation of streams along the roads and urban routes.

Lastly, it is worth recalling that the intensification of industrial development and agricultural activities and the consequent increasing water demand have recently led to overexploitation of local aquifers and amplification of compaction of compressible deposits and ground subsidence phenomena, further increasing the geological vulnerability of Perea [34,39]. In a scenario of increasing groundwater overexploitation of the aquifer system in the coastal zone of Thermaikos Municipality, land subsidence may become a further threat, principally in those areas where Quaternary alluvial formations are thick, with a lowering of the ground level.

\subsubsection{Exposure of the Built Environment}

Urban development in Perea has occurred in areas at the end of gullies, where pluvial and fluvial waters are naturally driven on their way to Thermaikos Bay. In cases where elevation rapidly decreases and considering the fact that those buildings are predominantly one- to two-storey residential dwellings, it can be easily concluded that they are largely exposed to impact from heavy rain and flooding events. This is a typical phenomenon in many southern European cities [39].

Moreover, in several cases, the street network of Perea constitutes a physical continuation of natural geomorphological features such as gullies, ravines and streams (Figure 10). Inevitably, stormwater is being conveyed to the urban fabric, increasing the exposure of local infrastructure. The energy of stormwater flow channelled along the roads can also push vehicles, garbage bins and any other large objects to create physical blockages of water flow (a dam effect) and obstructions to potential evacuation routes (see also pictures in [38]).

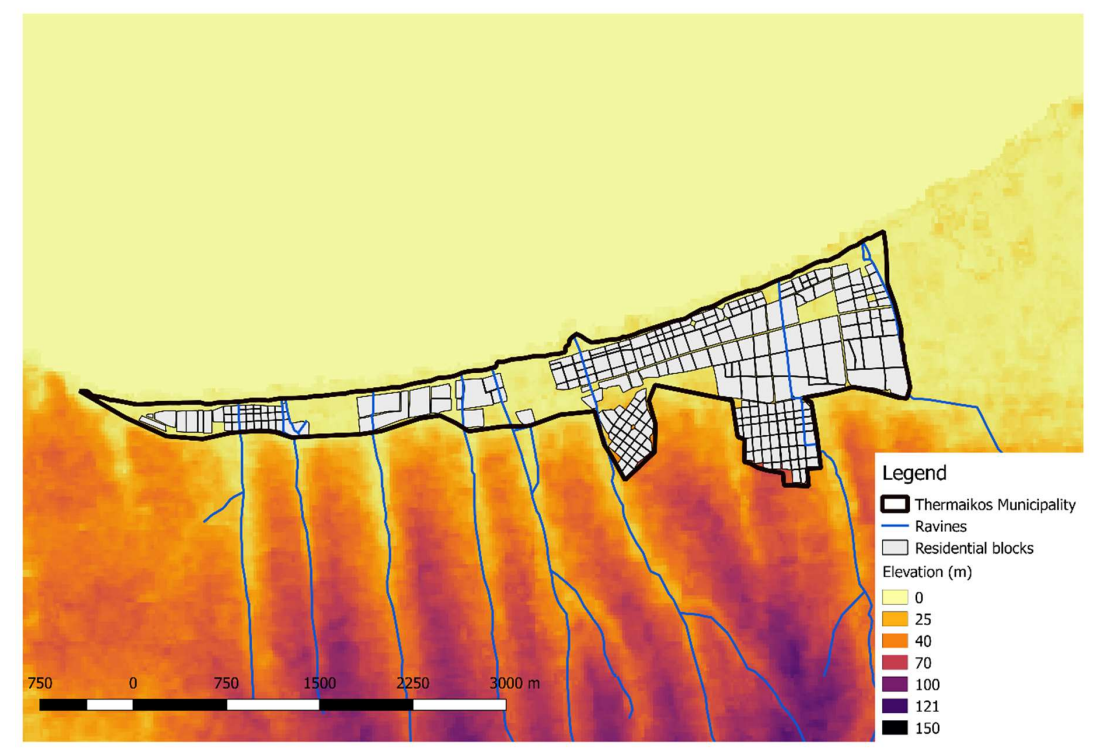

Figure 10. Digital elevation model of Thermaikos Municipality, with indication of the natural network of ravines, highlighting local topography and natural incisions passing through residential blocks in Perea. The downstream location of urban development is apparent.

A geospatial analysis of the natural environment where Perea village is located highlights the existence of such ravines upstream with regard to local settlements. The Municipality of Thermaikos is one the most rapidly developing suburbs of Thessaloniki, with an increasing urbanisation trend and substantial population growth after the 1990s (Figure 11). In more detail, between 1991 and 2011 the population of the Municipality increased by 150\%, with this increase reaching 35\% after 2001. This rapid urban development has left a significant spatial footprint in the Municipality, with semi-regulated dwellings sprouting all over the area, even in flood-prone zones. Although the current restrictions of the fiscal crisis have partially halted this rapid urban expansion, pressure on landscape 
and physical resources is more than evident. It should be mentioned here that the Municipality of Thermaikos, in its current form, was created through the Kallikratis Plan in 2011, after the merging of former municipalities and current municipal units of Epanomi, Michaniona and Thermaikos (smaller).

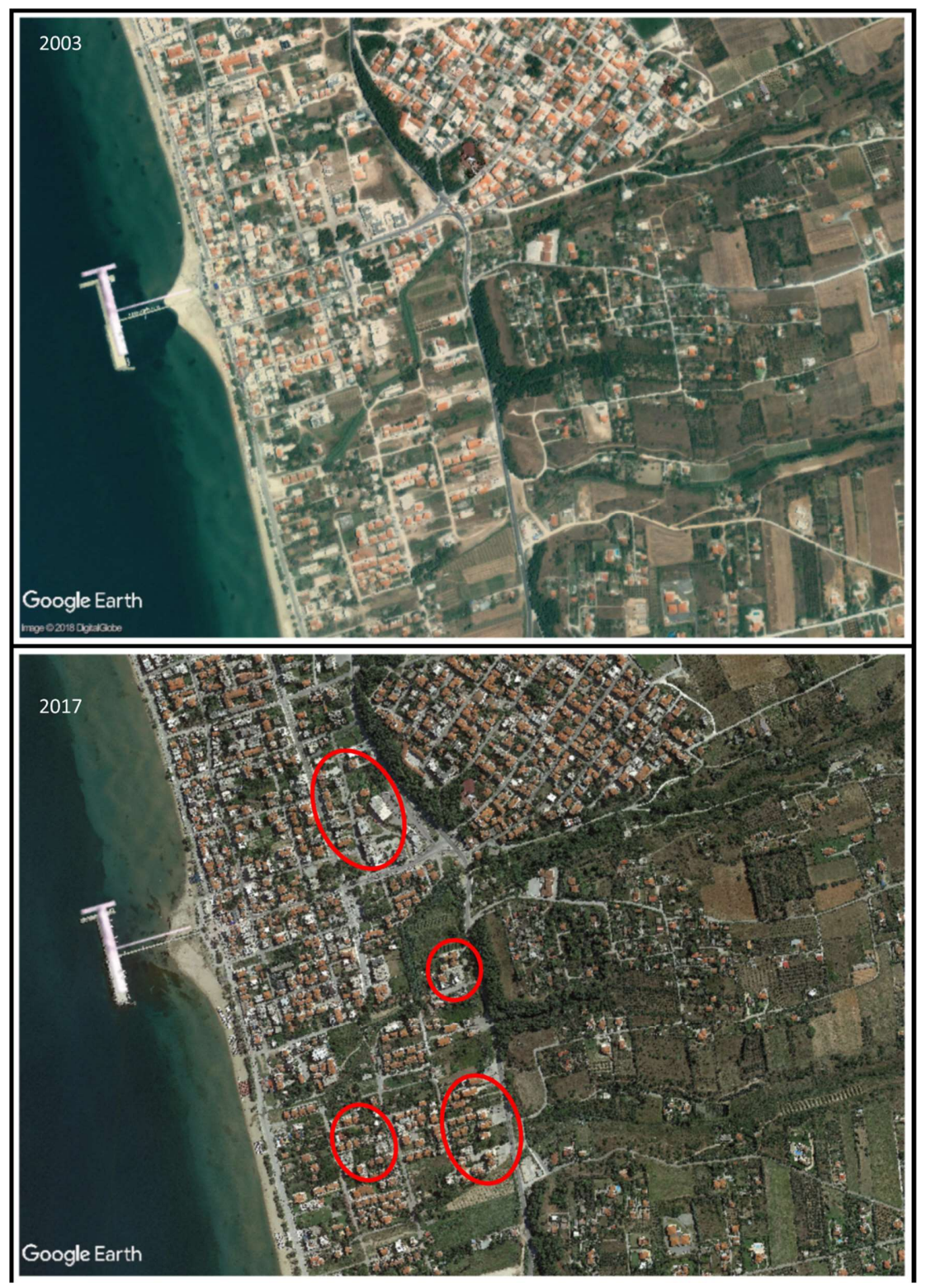

Figure 11. Evidence of recent urbanisation in Perea as captured from space from 2002 to 2016 (@ 2018 Google). Red circles highlight areas of new urban development and densification.

\subsubsection{Surface Flooding in Thessaloniki's RS}

Arguably, surface flooding has been more directly addressed in Thessaloniki's RS than seismic risk management. In fact, in Action 5 under Objective H in Goal 3 'Strengthen flood prevention', there is the only direct appreciation of the geological vulnerability of Thessaloniki, with a reference to the urban terrain. The Action also includes some future measures for flood risk management. The RS concludes that, despite the city's favourable topography, flood mitigation infrastructure in the metropolitan area needs substantial improvement. In the urban area specifically, poorly regulated urbanisation together with an obsolete sewerage system fail to handle peak water flows during flood events, while building density does not allow substantial retention or storage of stormwater, causing failure of the structures under extreme precipitation and resulting in flooding [13]. 
Nevertheless, there is a policy implementation gap also apparent here. Regardless of the ambitious nature of the flood prevention plan, flash floods in May 2018 [40] showed that such proposals have not yet been sufficiently operationalised. Also, the exposure of built environment is not adequately addressed, and thus urban planning is disconnected from the flood-prevention plan. A more robust regulatory framework that would prohibit urban development in flood-prone areas is not in place and, subsequently, future emergency responses will only be partially informed.

Finally, as Perea stands outside the jurisdiction of the municipality of Thessaloniki, but within its metropolitan area, it is unlikely to benefit from any future interventions towards flood prevention. However, as we have discussed, it is a highly flood-prone area accommodating an increasingly exposed built environment. The decision to focus on the municipality of Thessaloniki and not on the metropolitan area was made in order to manage the trade-off between offering a detailed analysis of the specific problems of a finite area and expanding to a larger metropolitan scale since city officials argued that both goals could not be practically achieved simultaneously.

\section{Discussion}

Integrating urban geological risk within Urban Resilience Strategies is a very challenging task. Through our case studies in Thessaloniki, we are presenting an approach to understanding urban geological risk connected to geohazards and the extent that this risk is being considered in Resilience Strategies. We conceptualised urban geological risk as geohazard $x$ geological vulnerability $x$ exposure of the built environment and chose earthquakes and surface flooding as the hazards for our analysis since they were recognised as the most imminent risks in Thessaloniki since the PRA. However, despite the initial appraisal, the published RS did not include sufficient actions to proactively tackle their potentially devastating impact.

This marginalisation of urban geological risk generates implementation challenges for Resilience Strategies. Thessaloniki's RS embodies a general aspiration of local authorities worldwide to harness the 'momentum' stimulated by the 'buzzword' resilience to reorganise the style of urban governance [41]. In this case, the municipal authority attempted to do so by allocating additional responsibilities to the local boroughs, strengthening the endogenous relations within the community and reinvestigating the city's relationship with the sea. The strategic developmental decision of emphasising in everyday resilience comes at the expense of geohazard management, particularly because local authorities feel that the city is 'less threatened by them compared to its timely socioeconomic slow-burn events', as stated by a high-ranked local official during one of the interviews undertaken in this study. Yet there seems to be little planning for preventing the impact of low-probability-high-magnitude events in the urban fabric.

Through our analysis we have noted three major implementation challenges for Thessaloniki's Resilience Strategy: a lack of geological insight in the design of Resilience Strategies, an inefficient relationship between the built environment and emergency planning, and problematic horizontal communication among the geologically related organizations. These challenges emerged through the synthesis of geological vulnerability and exposure of the built environment to urban geohazards with the policy implementation gaps, echoing our research approach.

\subsection{Lack of Geological Insight in the Design of Resilience Strategies}

Poor understanding and interpretation of subsurface urban ground conditions, which tend to vary due to multiple phases of development, especially in cities with a rich historical background, such as Thessaloniki, increase geological vulnerability and ultimately urban geological risk [42]. In our case study, this problematic understanding is clearly apparent in the RS, as geological references are not included in the document. Sporadic references to natural hazards can be identified throughout the document, without, however, a reference to the underlying geology.

The Acheiropoietos example demonstrates the heterogeneity of the city's geological conditions and the presence of a thick layer of urban fills in its historic centre, which affected the performance 
of the building stock during the 1978 earthquake. Similarly, the Quaternary superficial deposits in Thermaikos enable runoff water accumulation, contributing to surface flooding. Furthermore, the absence (and frequently circumvention) of a robust regulatory framework allowed urban development to occur in geomorphologically inappropriate locations, such as along ravines and at the end of gullies, which exacerbated the exposure of the built environment.

We believe that an appreciation of the underlying geology and geomorphology could provide helpful insights in strategic urban planning as it could decrease exposure to natural hazards by regulating urban expansion and providing further direction for urban development. For instance, despite the haste and sloppiness of development in the Thermaikos Municipality, its spatial footprint is reversible, as building densities are far lower than in the historic centre. Consequently, collaboration with geoscientists and geological organisations from the early stages of RS design and throughout the entire process of its implementation could result in a more thorough interpretation of subsurface ground conditions and ultimately in a more integrated resilience outcome.

\subsection{Relationship between the Built Environment and Emergency Planning}

Thessaloniki is characterised by hasty, informal and largely unregulated planning, which has led to a very dense urban core and uneven urbanisation in the outskirts. Through our analysis we demonstrate how irregular planning, coupled with non-appreciation of the geomorphological setting, increases geological vulnerability and exposure to earthquakes and surface flooding.

In Acheiropoietos, the presence of an ageing building stock is profoundly increasing exposure to earthquakes, as the past has already proven, particularly when combined with Thessaloniki's problematic urban planning milieu. Moreover, difficult access to free spaces is impeding the application of effective emergency planning responses. At the same time, in the Thermaikos municipality, urban development in the fringes of hilly formations and gullies and the design of street networks as a natural prolongation of local ravines in Perea facilitates the accumulation of rainwater, eventually increasing the exposure of adjacent urban settlements to surface flooding.

As a result, emergency planning in Thessaloniki seems to be hampered by the configuration of the built environment. This produces a great implementation challenge for the Resilience Strategy. On the one hand, the municipality's power to effectively intervene is limited, while on the other, invasive interventions to ameliorate the current situation would involve delicate negotiations with Thessaloniki's historical character and the need to keep all city layers connected [43].

We realise that such an endeavour would be particularly challenging, but we argue that the role of strategic planning is to facilitate such negotiations by directing developmental action to proactively address them.

\subsection{Horizontal Communication among the Geologically Related Organizations}

The RS is an overarching strategical document providing direction for future urban development. Therefore, its preparation and design should be an inclusive process among all urban stakeholders, facilitating the inter-municipal and inter-metropolitan communication routes or establishing them whenever absent. In the case of Thessaloniki, although one of the most substantial outcomes of the 100 RC Programme so far has been the gradual overcoming of this so-called 'silo-mentality' [44] and the beginning of trust-building among urban stakeholders operating within the Metropolitan area, geological organisations are not sufficiently represented in the discourse.

This communication gap is partially connected to the lack of geological insight we explored above, but it also derives from the complicated vertical responsibility allocation between different national administrative scales. Municipal and metropolitan organisations with a geological engagement are restricted by their authoritative power, while national ones depend on the political priorities of the central government. Eventually, no horizontal coordination is undertaken, and geological risk is not accounted for in the strategic planning level. 
The RS, as a strategical planning directive, should include a clear identification of the roles of organisations dealing with geological phenomena and a clarification of their tasks and jurisdictions. Then it could establish permanent communication channels among them and facilitate their effective connection with urban planning activities occurring on the ground.

\subsection{Lessons Learned}

Thessaloniki RS's inability to incorporate sufficiently urban geological risk reflects the complications of this matter. The inattention to urban geological conditions highlights the ineffective governance configuration within which many local administrations both within and outside the 100 Resilient Cities Network are operating and poses arduous implementation challenges for local authorities. The lack of geological insight, along with the disconnection between emergency planning and the built environment and the ineffective communication between the various geological organizations, negatively affect cities facing similar urban problems by amplifying their geological vulnerability and exposure to urban geohazards.

Emphasis on other urban priorities, coupled with problematic collaboration between municipal and environmental/geological authorities, creates a gap in the proper understanding of geological conditions and their interdependency, with increased unawareness of the environment resulting in a general failure to address these issues in local and metropolitan developmental policies. In the case of Thessaloniki, failure to address earthquakes and their repercussions is apparent, while, concurrently, flood prevention is being addressed much more adequately, with a turn towards green infrastructure and nature-based solutions, but without a holistic resilient vision.

In conclusion, Resilience Policies should create a vision for cities to achieve urban resilience by mobilising the local community, facilitating horizontal coordination of actions within public administration and nurturing a pre-emptive, resilience mentality. In this framework, wider appreciation of geological risk is fundamental in the process of dealing with uncertainty and pursuing urban resilience [45]. Consequently, the emerging implementation challenges deriving from the lack of this appreciation could be tackled through further engagement of geoscientists from the early stages of strategical urban planning, a clearer connection between emergency and urban planning and wider and more effective coordination among organizations responsible for dealing with geological vulnerability in urban settings.

\section{Conclusions}

Resilience Strategies have recently started to gain a central position among urban policy documents worldwide. The social turn of resilience's definition [46,47], however, leads to disparate levels of incorporation of geological risk, concurrently producing implementation challenges. In this article, we investigate the case of Thessaloniki, Greece, a city that was introduced to resilience principles for the first time in 2014 and published its Strategy in 2017. Through our analysis we demonstrate Thessaloniki's geological vulnerability as well as the exposure of its built environment to the most imminent type of urban geohazards for the city, earthquakes and surface flooding. After a review of the RS, we realised that there are specific policy implementation gaps, which will produce major implementation challenges for the city in the next stage of urban development.

We also acknowledge the limitations of our approach: we have not extensively discussed the specific policies by which Thessaloniki deals with geological risk; our goal was to emphasise the strategic planning level. This could be the focus of future research for the city, as well as the ways in which such policies could inform the RS and enhance urban resilience. Moreover, we realize that additional research is needed in other cities facing similar implementation challenges in order to generalise our outcomes, and we hope that this article could stimulate similar future studies.

The 100 Resilient Cities programme is the first attempt to introduce resilience in Thessaloniki's urban governance and policy-making. In contrast to other similar initiatives worldwide, Thessaloniki's resilience challenge did not emerge as a framework for absorbing, managing and preventing extrinsic 
shocks, but rather as a process of reorganising urban governance and shaping the developmental perspective of the city. Nevertheless, despite the widely successful implementation so far, there are crucial implementation challenges connected to geological hazards that need to be considered throughout Thessaloniki's journey towards urban resilience.

Author Contributions: V.P., D.T. and J.C. proposed the topic of the paper. V.P., D.T., J.C. and J.P.A. developed the methodological approach, while V.P. spearheaded the writing of the manuscript, with significant help from D.T. D.T. and L.K. assisted with the validation, while V.P. proceeded on the visualization, assisted by D.T. V.P., D.T., J.C., L.K. and J.P.A. helped in the design and supervision as well as review and editing of the paper.

Funding: This research was funded by EPSRC grant number EP/L016400/1.

Acknowledgments: The lead author gratefully acknowledges funding by the UK Engineering and Physical Sciences Research Council (EPSRC grant No. EP/L016400/1), the EPSRC Centre for Doctoral Training in Urban Science. The research presented in this article also received support from the British Geological Survey-University Funding Initiative (BUFI), with Deodato Tapete acting as Principal Investigator of the BUFI funds and PhD supervisor of Vangelis Pitidis at BGS and later in the framework of international research collaboration to finalise the analysis and publication of the results. Deodato Tapete publishes with the permission of the Executive Director of the British Geological Survey (NERC). Leon Kapetas' collaboration was supported by the EPSRC grants, No. EP/P004180/1 (Nottingham University) and EP/P004431/1 (Cambridge University). The authors would also like to thank Thessaloniki's Resilience Office for their kind collaboration in the conduction of interviews, as well as Dimitris Pitilakis and Sotiris Argyroudis from the SDGEE Research Unit of the Aristotle University of Thessaloniki for the provision of some of the datasets used in this article.

Conflicts of Interest: The authors declare no conflict of interest. The founding sponsors had no role in the design of the study; in the collection, analyses, or interpretation of data; in the writing of the manuscript, and in the decision to publish the results.

\section{Appendix A}

Table A1. Spatial data and imagery used to investigate the relationship between geohazards and urbanisation in Thessaloniki, Greece.

\begin{tabular}{|c|c|c|}
\hline Dataset & Source & Year \\
\hline Administrative boundaries & Thessaloniki GIS portal (https:/ / gis.thessaloniki.gr/) & 2018 \\
\hline $\begin{array}{l}\text { Geological Map of Greece-Thessaloniki } \\
\text { Sheet (scale 1:50,000) }\end{array}$ & Institute of Geological and Mining Research of Greece & 1978 \\
\hline $\begin{array}{l}\text { Engineering Geology Map of the } \\
\text { Thessaloniki Wider Area (scale 1:50,000) }\end{array}$ & Institute of Geology and Mineral Exploration (IGME) & 2000 \\
\hline Earthquakes over 4.0 Richter Magnitude & $\begin{array}{l}\text { National Observatory of Greece, Institute of } \\
\text { Geodynamics (http:/ / www.gein.noa.gr/en/seismicity/ } \\
\text { earthquake-catalogs) }\end{array}$ & 2017 \\
\hline $\begin{array}{l}\text { Database of high-impact weather events in } \\
\text { Greece (2001-2012) }\end{array}$ & $\begin{array}{l}\text { National Observatory of Athens (NOA), } \\
\text { Papagiannaki et al. [30] }\end{array}$ & 2013 \\
\hline Floods in Greece (1880-2010) & Diakakis et al. [29] & 2012 \\
\hline On-Line Flood Database for Greece & Nikolaidou et al. [31] ceogis-floods.web.auth.gr & 2014 \\
\hline $\begin{array}{l}\text { Building uses in Thessaloniki Metropolitan } \\
\text { Area }\end{array}$ & Thessaloniki GIS portal (https:/ / gis.thessaloniki.gr/) & 2018 \\
\hline Building geometry (from Open Street Maps) & Open Street Maps (https:/ / www.openstreetmap.org/) & 2018 \\
\hline Geotectonical zones of Northern Greece & Makedon et al. [16] & 2009 \\
\hline Urban fill thickness & Makedon et al. [16] & 2009 \\
\hline Land cover map & $\begin{array}{l}\text { Copernicus Land Monitoring Service, Urban Atlas } \\
\text { (https://land.copernicus.eu/) }\end{array}$ & 2006 \\
\hline $\begin{array}{l}\text { High-resolution satellite optical imagery } \\
(2003-2017)\end{array}$ & Google Earth, Bingmap & 2017 \\
\hline Digital Elevation Model (DEM) & USGS (https:/ / earthexplorer.usgs.gov /) & 2000 \\
\hline Hydrology & $\begin{array}{l}\text { http:// data.gov.gr/, and digitised based on Google } \\
\text { Earth and DEM }\end{array}$ & 2018 \\
\hline
\end{tabular}




\section{References}

1. Welsh, M. Resilience and responsibility: Governing uncertainty in a complex world. Geogr. J. 2014, 180, 15-26. [CrossRef]

2. Alexander, D.E. Resilience and disaster risk reduction: An etymological journey. Nat. Hazards Earth Syst. Sci. 2013, 13, 2707-2716. [CrossRef]

3. Meerow, S.; Newell, J.P.; Stults, M. Defining urban resilience: A review. Landsc. Urban Plan. 2016, 147, $38-49$. [CrossRef]

4. Coaffee, J.; Clarke, J. On securing the generational challenge of urban resilience. Town Plan. Rev. 2015, 28, 323-339. [CrossRef]

5. United Nations General Assembly. Report of the Open-Ended Intergovernmental Expert Working Group on Indicators and Terminology relating to Disaster Risk Reduction; United Nations General Assembly: New York, NY, USA, 2017.

6. Davoudi, S. Resilience: A Bridging Concept or a Dead End? Plan. Theory Pract. 2012, 13, 299-307. [CrossRef]

7. Rockefeller Foundation 100 Resilient Cities. Available online: http://www.100resilientcities.org/ (accessed on 7 October 2018).

8. Da Silva, J.; Moench, M. City Resilience Framework. Arup 2014. Available online: http:/ /www.seachangecop. org/files/documents/URF_Bo (accessed on 7 October 2018).

9. Bourgon, J. New directions in public administration: Serving beyond the predictable. Public Policy Adm. 2009, 24, 309-330. [CrossRef]

10. Matyas, D.; Pelling, M. Positioning resilience for 2015: The role of resistance, incremental adjustment and transformation in disaster risk management policy. Disasters 2015, 39, s1-s18. [CrossRef] [PubMed]

11. Boin, A.; van Eeten, M.J.G. The Resilient Organization. Public Manag. Rev. 2013, 15, 429-445. [CrossRef]

12. Taleb, N.N. The Black Swan: The Impact of the Highly Improbable; Penguin Books Ltd.: London, UK, 2007; ISBN 140006351597814000635129780713999952.

13. Thessaloniki Resilience Team. Thessaloniki: Preliminary Resilience Assessment; Municipality of Thessaloniki: Thessaloniki, Greece; Metropolitan Developmental Agency of Thessaloniki S.A.: Thessaloniki, Greece, 2016.

14. Thessaloniki Resilience Team. Resilient Thessaloniki: A Strategy for 2030; Municipality of Thessaloniki: Thessaloniki, Greece; Metropolitan Developmental Agency of Thessaloniki S.A.: Thessaloniki, Greece, 2017.

15. Crowe, P.R.; Foley, K.; Collier, M.J. Operationalizing urban resilience through a framework for adaptive co-management and design: Five experiments in urban planning practice and policy. Environ. Sci. Policy 2016, 62, 112-119. [CrossRef]

16. Makedon, T.; Chatzigogos, N.P.; Spandos, S. Engineering geological parameters affecting the response of Thessaloniki's urban fill to a major seismic event. Eng. Geol. 2009, 104, 167-180. [CrossRef]

17. Berkes, F.; Ross, H. Community Resilience. Toward an Integrated Approach. Soc. Nat. Resour. 2013, 26, 5-20. [CrossRef]

18. Galderisi, A.; Ferrara, F.F. Enhancing Urban Resilience in Face of Climate Change. TEMA J. L. Use Mobil. Environ. 2012, 5, 69-88. [CrossRef]

19. Manos, G. Greece. In International Handbook of Earthquake Engineering; Paz, M., Ed.; Springer: Boston, MA, USA, 1994; ISBN 978-1-4613-5859-6.

20. Vayona, A. Investigating the preferences of individuals in redeveloping waterfronts: The case of the port of Thessaloniki - Greece. Cities 2011, 28, 424-432. [CrossRef]

21. Raspini, F.; Loupasakis, C.; Rozos, D.; Adam, N.; Moretti, S. Ground subsidence phenomena in the Delta municipality region (Northern Greece): Geotechnical modeling and validation with Persistent Scatterer Interferometry. Int. J. Appl. Earth Obs. Geoinf. 2014, 28, 78-89. [CrossRef]

22. Charles, J.A.; Watts, K.S. Building on Fill: Geotechnical Aspects; IHS: Bracknell, Berkshire, UK, 2015; ISBN 9781906846220.

23. Raspini, F.; Loupasakis, C.; Rozos, D.; Moretti, S. Advanced interpretation of land subsidence by validating multi-interferometric SAR data: The case study of the Anthemountas basin (Northern Greece). Nat. Hazards Earth Syst. Sci. 2013, 13, 2425-2440. [CrossRef] 
24. Pitilakis, K.; Anastasiadis, A.; Kakderi, K.; Argyroudis, S.A.; Alexoudi, M. Vulnerability Assessment and Risk Management of Lifelines, Infrastructures and Critical Facilities. The Case of Thessaloniki's Metropolitan Area. In Proceedings of the 4th International Conference on Earthquake Geotechnical Engineering, Thessaloniki, Greece, 25-28 June 2007; pp. 1-15.

25. Penelis, G.G.; Sarigiannis, D.; Stavrakakis, E.; Stylianidis, K.C. A statistical evaluation of damage to buildings in the Thessaloniki, Greece, earthquake of June, 20, 1978. In Proceedings of the 9th World Conference on Earthquake Engineering, Tokyo, Japan, 2-19 August 1989; pp. 187-192. Available online: http:/ /www.iitk. ac.in/nicee/wcee/article/9_vol7_187.pdf (accessed on 7 October 2018).

26. Kappos, A.J.; Panagopoulos, G.; Penelis, G.G. Development of a seismic damage and loss scenario for contemporary and historical buildings in Thessaloniki, Greece. Soil Dyn. Earthq. Eng. 2008, 28, 836-850. [CrossRef]

27. Riga, E.; Karatzetzou, A.; Mara, A.; Pitilakis, K. Studying the uncertainties in the seismic risk assessment at urban scale applying the Capacity Spectrum Method: The case of Thessaloniki. Soil Dyn. Earthq. Eng. 2017, 92, 9-24. [CrossRef]

28. Gospodini, A. Economic Crisis and the Shrinking Greek Cities. In Proceedings of the 1st International Conference on Architecture \& Urban Design, Tirana, Albania, 19-21 April 2012; pp. 685-702.

29. Diakakis, M.; Mavroulis, S.; Deligiannakis, G. Floods in Greece, a statistical and spatial approach. Nat. Hazards 2012, 485-500. [CrossRef]

30. Papagiannaki, K.; Lagouvardos, K.; Kotroni, V. A database of high-impact weather events in Greece: A descriptive Atmospheric impact analysis for the period 2001-2011. Nat. Hazards Earth Syst. Sci. 2013, 13, 727-736. [CrossRef]

31. Nikolaidou, M.; Mouratidis, A.; Doxani, G.; Oikonomidis, D.; Tsakiri-Strati, M.; Sart, F. An on-line flood Database for Greece supported by Earth Observation Data and GIS. In 10th International Geographical Congress of Hellenic Geographical Society; Hellenic Geographical Society: Thessaloniki, Greece, 2014; pp. 662-670.

32. Cao, C.; Xu, P.; Wang, Y.; Chen, J.; Zheng, L.; Niu, C. Flash flood hazard susceptibility mapping using frequency ratio and statistical index methods in coalmine subsidence areas. Sustainability 2016, 8, 948. [CrossRef]

33. Gaume, E.; Bain, V.; Bernardara, P.; Newinger, O.; Barbuc, M.; Bateman, A.; Blaskovicova, L.; Bloschl, G.; Borga, M.; Dumitrescu, A.; et al. A compilation of data on European flash floods. J. Hydrol. 2009, 367, 70-78. [CrossRef]

34. Anastasiadis, A.; Raptakis, D.; Pitilakis, K. Thessaloniki's detailed microzoning: Subsurface structure as basis for site response analysis. Pure Appl. Geophys. 2001, 158, 2597-2633. [CrossRef]

35. Papadopoulou, I.; Tziavos, I.N.; Savvaidis, P. Remote Sensing and Geographic Information Systems (GIS) Contribution to the Inventory of Infrastructure Susceptible to Earthquake and Flooding Hazards in North-Eastern Greece. Geosciences 2012, 2, 203-220. [CrossRef]

36. Verani, E.; Pozoukidou, G.; Sdoukopoulos, A. The effect of urban density, green spaces and mobility patterns in cities' environmental quality: An empirical study of the metropolitan area of Thessaloniki. Spatium 2015, 1, 8-17. [CrossRef]

37. Yamamoto, K.; Li, X. Safety Evaluation of Evacuation Routes in Central Tokyo Assuming a Large-Scale Evacuation in Case of Earthquake Disasters. Risk Financ. Manag. 2017, 10, 14. [CrossRef]

38. BBC News. Greece Flash Floods Leave At Least Three Dead. Available online: http://www.bbc.co.uk/ news / world-europe-37295180 (accessed on 7 September 2016).

39. Raspini, F.; Bianchini, S.; Moretti, S.; Loupasakis, C.; Rozos, D.; Duro, J.; Garcia, M. Advanced interpretation of interferometric SAR data to detect, monitor and model ground subsidence: outcomes from the ESA-GMES Terrafirma project. Nat. Hazards 2016, 83, 155-181. [CrossRef]

40. Watchers Heavy Rain, Hail and Floods Hit Thessaloniki, Greece. Available online: https:/ /watchers.news / 2018/05/11/heavy-rain-hail-and-floods-hit-thessaloniki-greece/. (accessed on 7 October 2018).

41. Duit, A. Resilience Thinking: Lessons for Public Administration. Public Adm. 2016, 94, 364-380. [CrossRef]

42. Bricker, S.; Reeves, H.; Campbell, S.D.G.; Price, S. The Ground Beneath Cities: Where Should Future Development Occur? 2012. Available online: https://assets.publishing.service.gov.uk/government/ uploads/system/uploads/attachment_data/file/461947/future-cities-ground-beneath.pdf (accessed on 7 October 2018). 
43. Tapete, D. Book Review: Reconnecting the City, Bandarin, Francesco \& van Oers, Ron (eds.), John Wiley \& Sons, Ltd., Oxford, UK, 2014, (344 pp.). Cities 2016, 56, 99-100. [CrossRef]

44. Coaffee, J.; Therrien, M.-C.; Chelleri, L.; Henstra, D.; Aldrich, D.; Mitchell, C.; Tsenkova, S.; Rigaud, E. Urban resilience implementation: A policy challenge and research agenda for the 21st century. J. Contingencies Cris. Manag. 2018, 26, 403-410. [CrossRef]

45. Lu, P.; Stead, D. Understanding the notion of resilience in spatial planning: A case study of Rotterdam, The Netherlands. Cities 2013, 35, 200-212. [CrossRef]

46. Adger, N. Social and ecological resilience: Are they related? Prog. Hum. Geogr. 2000, 3, 347-364. [CrossRef]

47. Brown, K. Global environmental change I: A social turn for resilience? Prog. Hum. Geogr. 2014, 38, $107-117$. [CrossRef]

(C) 2018 by the authors. Licensee MDPI, Basel, Switzerland. This article is an open access article distributed under the terms and conditions of the Creative Commons Attribution (CC BY) license (http:/ / creativecommons.org/licenses/by/4.0/). 